\title{
Framework for E-learning in Higher Institutions of Learning in Developing Countries: A Systematic Review of Literature
}

\author{
Lawrence Nkamwesiga \\ Muni University, Faculty of Techno-Science, Department of Computer and Information Science
}

\begin{abstract}
The concept of e-learning is a new phenomenon emerging in developing countries, an understanding of e-learning as a pedagogical process is crucial especially with the global proliferation of Information and Communication Technologies(ICTs). Elearning is an emerging pedagogical phenomenon that developing counties have not embraced fully due to its challenges associated with various implementation factors. A systematic review of 78 e-learning published research articles was conducted and gaps were analyzed in the existing research and recommendations with a focus on developing countries. The purpose of the study was to establish evidence among researchers for e-learning challenges in developing countries with focus on Ugandan public universities. The synthesis of selected articles resulted into identification of recurring trends, crucial knowledge gaps, and a road map that shows the current state of e-learning in developing countries. The articles were taken from various African countries located in the sub-Saharan region that exhibited similar challenges of implementing e-learning in developing countries. Other developing countries in Europe, Middle East, south pacific, and Australia were included in the review. In an endeavor to produce unbiased results, the quality of the papers was critically observed by considering only peer reviewed articles published in recognized journals within the last 5 years. That would guide researchers, practitioners, implementers such as governments that would like to conduct research in the emerging e-learning as a crucial pedagogical process in the field of knowledge transfer and teaching.
\end{abstract}

Keywords: Developing Countries, e-learning, Public Universities, Systematic literature Review

\section{Introduction}

The phenomenon of e-learning as a pedagogical tool became evident in 1999 when the word was the first used Computer Based Training Program (CBT Program) [1]. The use of ICTs has changed since then and there is enough evidence to show that there has been significance in the usage and application of ICTs without excluding the internet since 1999. The process of learning using electronic media particular the internet is what is known as e-learning. The elearning process has evolved with evolving e-learning platforms. E-leaning platform is the medium upon which elearning takes place and implements systems such as Learning Management System(LMS) that extend various futures such as discussion forums, instructor interaction with the learners through synchronous and asynchronous service delivery.

E-learning (electronic learning) is a pedagogical training process that involves the transfer of knowledge through electronic means as opposed to its counterpart traditional pedagogical training process where knowledge transfer is face-to-face(f2f). The e-learning process takes place over elearning (electronic learning) platforms such as the Moodle Platform. In order for e-learning to be effectively implemented, it requires e-learning platforms that are used to manage the learning processes such as holding discussion forums, interactive dashboards, assignment submission and quizzes.

It is worth to note that various definitions and theories do exist for e-learning. Others define e-learning as long distance learning, virtual learning or electronic learning. [2] defines elearning as electronic learning typically using a computer to deliver knowledge. However, this definition of eLearning does give a clear description of e-learning as e-learning encompasses a wide range of on line initiatives and can be thought of as the use of electronic media: computers, tablets, phones, laptops for pedagogical purposes. It is important to note that although definitions and theories do exit, there is still more to be done to enable e-learning implementers and consumers understand crucial challenges underpinning the elearning phenomenon. According to [1], e-learning is a pedagogical tool that is based on a computer to deliver educational material with the operation of an instructor whereby the learner can access educational services from anywhere and at any time provided there is internet connectivity.

E-learning tends to provide the best and quickest ways for knowledge in Universities. A University is an academic level of education where learners tend to specialize in their areas of studies and thus vast knowledge resources are needed for compressive reading. E-learning in developing countries particularly in public universities has not been implemented fully due to challenges facing these countries. The e-learning implementation challenges facing developing countries in the sub-Saharan region are the main topic of this study.

\subsection{Background}

The literature reviews on e-learning started emerging since 1990s. The penetration of Information and Telecommunication Technology(ICT) has increased greatly. The use of ICT has merged into what is called the internet of things(IoT). The internet of things is the interconnectivity of things otherwise known as objects that communicate to themselves or to human beings via a given media. Moreover,

\section{Volume 6 Issue 12, December 2017}




\section{International Journal of Science and Research (IJSR) \\ ISSN (Online): 2319-7064}

Index Copernicus Value (2015): 78.96 | Impact Factor (2015): 6.391

things can also talk to other things via a medium that is protocol controlled. Phones, computers, laptops, palmtops, and smartphones are ICT devices that have picked usage over last few years belong to this family.

The study presents a review of e-learning implementation challenges in developing countries, evaluating developments in the research subject, assessing the current phenomenon and directions of research while concentrating on what have been done, the gaps in what has been not done, and what other scholar may need to put emphasis on. A broader understanding of challenges in implementing e-learning in developing countries will facilitate in higher education institutions in developing countries.

\subsection{Research questions}

- What is the scope of e-learning?

- What are the research gaps in the current e-learning literature?

- What are the theories used in explaining the e-learning implementation?

- What are the challenges faced by Higher institutions of learning in developing countries to implement e-learning?

\section{Methodology}

The procedure used to elect the articles was adapted from the concept that a review if it is to be systematic it must be based on well framed questions, relevant studies, assesses their quality and outlines the proof by use of clear methodology [3]. Academic literature revealed that systematic review is unique from the traditional reviews and commentaries because it is a clear and systematic method [3].

\subsection{Articles Selection Strategy}

Selecting articles up on which to base the study was a challenging phenomenon as e-learning in developing countries is still a new and not fully exploited pedagogical training framework. The standard journals such as: Journal of the Royal Society of Medicine (JRSM), Knowledge Management \& E-Learning(KME): An International Journal; International Review of Research in Open and Distributed Learning(IRRODL); Journal of Computer Assisted Learning (JCAL); were a key consideration for section of articles. The databases used for selection of the articles was google scholar, IEEE, IEEE Xpore Digital Library, Australian Journal of Teacher Education(AJTE); Global Journal of Human-Social Science(GJSS); e-Journal of Business Education \& Scholarship of Teaching(EJBEST), Journal of Workplace Learning(JWL), International Review of Research in Open and Distributed Learning(IRRODL)

Articles that had digital object identification(DOI) tags were given more consideration.

\subsection{Inclusion Criteria}

The criteria to select the articles was also determined. Not every article qualified. The articles were selected using the following inclusion and exclusion.

\subsubsection{Included}

- Published research articles from journals and

- conferences between 2010 and 2016,

- Articles that included e-learning and its challenges with focus on developing countries particularly in Ugandan public universities

- Articles from countries that are already practicing elearning that share common border with Uganda and developing countries

\subsubsection{Excluded}

- Articles that were published before 2010 were not considered

- Articles addressing e-learning challenges outside developing countries

- Articles that are government reports, white papers, and projects

- Articles that not focus on e-learning in primary and secondary schools

\subsubsection{Search terms}

Appropriate search terms were used to aid retrieval of relevant articles. Phrases such as e-learning in developing countries, e-leaning and challenges in East African public universities, E-learning and challenges in Uganda public universities, and E-learning in sub-Saharan region. The better search results were obtained when a such containing the hyphen (-) after e was used. The method above yielded 130 articles that were later fileted for use in this study.

\subsubsection{Tools used}

The tools used for analyzing the qualitative data for 130 full text articles were the literature review matrix and Nvivo 11 software.

\section{Quality Control}

A further scrutiny of the full text articles was done for quality assurance. This was particularly done to investigate if articles were duplicated in the library. The review gave 78 full text articles that was considered for this study.

\section{Discussion and Presentation of Results}

A total of 78 full articles selected were categorized according to content. The categorized articles were further analyzed by: considering articles from recognized publication journals and conferences, distribution of the articles by regions, and considering the year of publication. That give an idea on elearning challenges in developing countries that was used to answer the formulated research questions.

\subsection{Distribution of Articles by Year of Publication}

The articles were selected and distributed according to years of publication from 2004 to 2016 . This criterion was used to provide a wider scope of evidence to achieve the scope specified in the research question. The years up on which the study was based to determine the number of articles for use in this study are as shown in figure 1 below. The trend depicts the years in which e-learning became popular. 


\section{International Journal of Science and Research (IJSR) \\ ISSN (Online): 2319-7064}

Index Copernicus Value (2015): 78.96 | Impact Factor (2015): 6.391

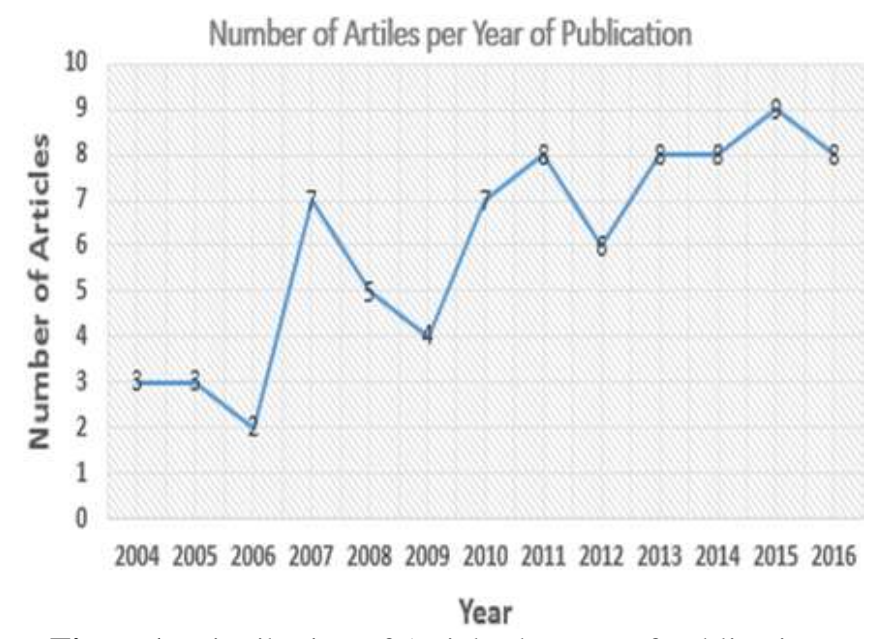

Figure1: Distribution of Articles by year of publication

\subsection{Distribution of Articles by Regions}

In this study, frequency of distribution of literature in figure 4.2 below shows that most research is done in Africa (21 articles, 26.9 percent), Middle-East (18 articles, 23.1 percent), Australia (16 articles, 20.5 percent), Europe (15 articles, 19.2 percent), and South Pacific (8 articles, 10.3 percent) with the lowest frequency number.

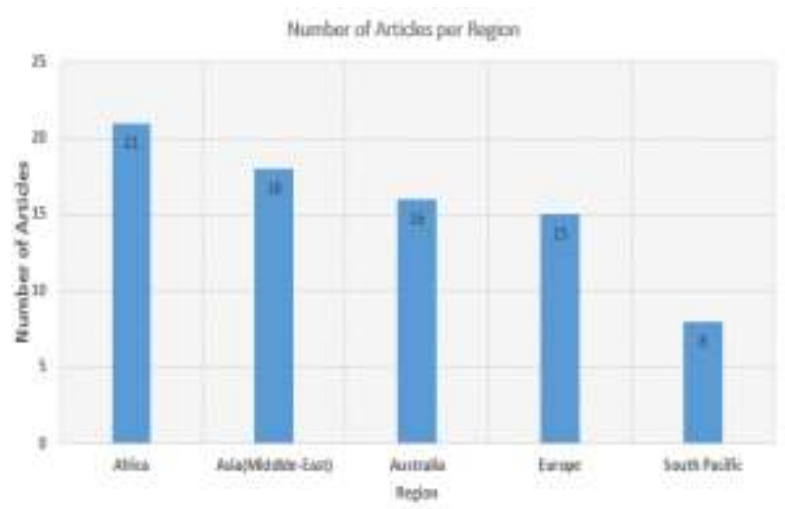

Figure 2: Distribution of Articles by Regions

The study showed that Africa dominates because most developing countries that have e-learning implementation challenges are located in Africa characterized by relatively low Information and Communication Technology(ICT) infrastructure. Asia(Middle-East) follows an indication that some countries located in this region also have e-learning implementation challenges. On the other hand, countries that have low frequency literature numbers have less eLearning implementation challenges.

\subsection{Classification Categories}

To guide the study articles were arranged into three main categories. The first category included research papers that combined theory and data: case studies, survey, content analysis, and interview with data (50 articles, 64.1 percent). The second category was that of conceptual papers that included papers with no factual information, no data, with some theoretical discourse and case examples (18 articles, 23.1percent). The last category included opinions and viewpoints from academic practitioners (10 articles, 12.8 percent)

\subsection{Research Methods}

Articles were categorized according to the research methods that were by the authors. Table 1 below was used as a guide to categorize the articles into various research methods. In order for an article to qualify for selection, it first either met one or two of the category check list shown in figure 4.1 above. The previous studies on e-learning challenges in developing countries showed that much of the research has been done on case studies (20 articles, 25.64 percent) or has been considered in the form of content or discourse analysis (13 articles, 16.67 percent) while a chunk has taken the form of Conceptual or Opinion (28 articles, 38.9 percent) as shown in table 2 . below.

Table 1: Article Classification Based on the Research Method

\begin{tabular}{|c|c|c|c|}
\hline Catesory & Sub-category & Data Collection Method & Metheds of Analysis \\
\hline $\begin{array}{l}\text { Conceptial } \\
\text { (Explocenory } \\
\text { studies) }\end{array}$ & NA & $\begin{array}{l}\text { - No data } \\
\text { theory discressices } \\
\text { only }\end{array}$ & NA \\
\hline \multirow[t]{2}{*}{ Research $P_{2 y e r s}$} & Quzlatative & $\begin{array}{l}\text { - Convenient Method } \\
\text { - Primary Dista } \\
\text { - Secoudary Data } \\
\text { - Direct Observitioa }\end{array}$ & $\begin{array}{l}\text { - Coding } \\
\text { - Grounded Theory } \\
\text { - Case study }\end{array}$ \\
\hline & Quantrtatrve & $\begin{array}{l}\text { - Survez method } \\
\text { - Case study } \\
\text { - Content Aralyuis }\end{array}$ & $\begin{array}{l}\text { - Descriptive statisticic } \\
\text { - Cross Tabulatioess }\end{array}$ \\
\hline
\end{tabular}

There has been a trace of quantitative research on e-learning challenges in developing countries (11 articles, 14.1 percent). The empirical studies included survey, survey and questioners, content analysis, interviews and focus groups, documents and secondary data (existing data) as the data collection method. Of the 11 articles that used quantitative research methods 9 used survey and questionnaires. Higher Institutions of Learning(HIL) (private universities, government universities, colleges) were the focal point (unit of analysis) for all the empirical studies.

Tale 2: Number of Articles by Research Method

\begin{tabular}{lcc}
\hline Research Methods & Number of Articles & Percentage \\
\hline Quantitative Research Papers & 11 & 14.10 \\
Qualitative Research Papers & 6 & 7.69 \\
(Participant survey) & & \\
Case studies & 20 & 25.64 \\
Content Analysis & 13 & 16.67 \\
Conceptual/Opinion & 28 & 35.90 \\
Total & 78 & 100 \\
\hline
\end{tabular}

\subsection{Theoretical Frame Work Foundations}

Less theoretical research has been done on the e-learning challenges in developing countries as the field of e-learning is still uncertain in some developing world. There is no theory that exists particularly for e-learning challenges in developing countries. The various theories that have been developed for e-learning challenges in developing countries, according to literature reviews included: Unified Theory Acceptance and User Model(UTAUT) [4], [5], [6], Diffusion of Technological Innovation Theory (DTIT) [7] and Holistic

\section{Volume 6 Issue 12, December 2017}




\section{International Journal of Science and Research (IJSR) \\ ISSN (Online): 2319-7064}

Index Copernicus Value (2015): 78.96 | Impact Factor (2015): 6.391

e-learning systems theoretical framework [8]. These theories generalize eLearning challenges but are not specific for developing countries. The theories mentioned above were considered to be comprehensive in addressing the crucial factors affecting e-learning implementation challenges in terms of behavioral, technology, and institution structures that would be applied in developing countries.

\section{The Scope of E-learning implementation challenges}

E-learning has always been associated with virtual learning, electronic learning, digital learning, internet learning, learning using a computer, or learning via the television. The definition of e-learning is not constant. In this literature review drawing a distinct line between these definitions was a challenging situation. After reviewing various articles on elearning, the common definition adapted defined e-learning as a pedagogical tool that aims at delivering knowledge content using electronic media. The electronic media can be a computer, telephone, laptop, palm top, and internet. The study of the literature in e-learning implementation indicated that there are challenges associated with e-learning implementation in developing countries. These challenges obtained from various articles addressing e-learning in developing countries further indicated similarities in the challenges associated with e-learning implementation in higher institutions of learning.

The unit of study in the literature review has been in higher intuitions of learning that are government owned commonly known as public universities where implementation of elearning is seen as the top-down approach. The literature further helped to identify the challenges related to e-learning in higher institutions of learning in developing countries.

The theories encountered in this study while reviewing the literature: Unified Theory Acceptance and User Model(UTAUT), Diffusion of Technological Innovation Theory(DTIT), and Holistic e-learning systems theoretical framework(HELST) served as a gauge to understand the challenges of implementing e-learning in higher institutions of learning in developing countries and how to address these challenges. The literature review revealed the following elearning implementation challenges in developing countries:

1) Lack of Systematic approach to ICT implementation

2) Lack of awareness of ICTs

3) Poor altitude about e-learning

4) Low support from administration

5) Stakeholders not fully involved

6) Lack of ownership

7) Inadequate funding

8) Mindset

9) Language barrier

10) Poor internet connectivity

11) Un reliable poor supply

12) In adequate ICTs

13) Pirated e-learning platforms

14) Lack of e-learning centers

15) Poor or non-operational e-learning policies

\section{Framing e-Learning Implementation}

The three theories mentioned above formed the baseline upon which two theories emerged: Basic E-learning Theory(BET) and Comprehensive e-learning Systems Conceptual framework(CESCF). The framework shown in figure 3 below demonstrates the constructs necessary for transforming an e-learning system into a standard e-learning system while addressing the major challenges of e-learning implementation, the outcomes if the challenges are overcome. On the other hand, the framework shown in figure 4 combines all the constructs into a compressive framework. The major constructs that helped to come up with framework were: E-learning systems stakeholders(people), E-learning Systems(Technology), E-learning Activities(Services), and E-learning System Support.

\subsection{E-learning Systems Stakeholders(people)}

The e-learning systems stakeholders include people, stakeholder, customers: Students, Employees, Community; Suppliers: Educational Institutions, Government, Teachers, Technology Providers, Partners, Donors, Internet Providers, Accreditation bodies; Board \& shareholder: Education ministry, industry; Professional Associations, and Student Commissions.

\subsection{E-learning Systems Technology (Learning Technology)}

The e-learning systems technology construct include Learning Technology Content: Document, Digital audio and video, search engines, assessment, and post area. Furthermore, e-learning systems technology construct include communication: discussion area, forum, chat, blackboard, tools, e-mail, and synchronous communication. In this study e-learning systems technology was considered to be the means through which learning takes place.

\subsection{E-Learning Activities (Services)}

These are activities that provide services in form of knowledge, sensitization pedagogical models, and instructional. The knowledge construct includes: training, familiarity, practice, demonstrations, and simulation. There must be sensitization about e-learning while it is being implemented. Another construct to be put into consideration is the pedagogical model. This includes: open learning, distributed learning, communities of practice, and knowledge. Lastly, the instructional service that includes: activating learner, assessing learner outcomes, sequencing processes, and collaboration.

\subsection{E-learning Systems Support(Support)}

This is the construct that supports e-learning systems. In the previous literature, this construct was not included in the framework. This is a very important construct which includes: Utilities; Power supply, High bandwidth, and New Technology Networks(NTN); and ICTs Infrastructure, Internet, Network, E-Platforms, and E-learning centers.

Volume 6 Issue 12, December 2017 


\section{International Journal of Science and Research (IJSR) \\ ISSN (Online): 2319-7064}

Index Copernicus Value (2015): 78.96 | Impact Factor (2015): 6.391

The 4 constructs above formed the basis of 2 frameworks created in this study which include: people, services, technology, and support. The 4 approaches lead to the design and development of two frameworks shown figure 3 and figure 4 below. The review of literature lead to the comprehensive-standard e-learning framework that could be used to manage e-learning implementation challenges in developing countries.

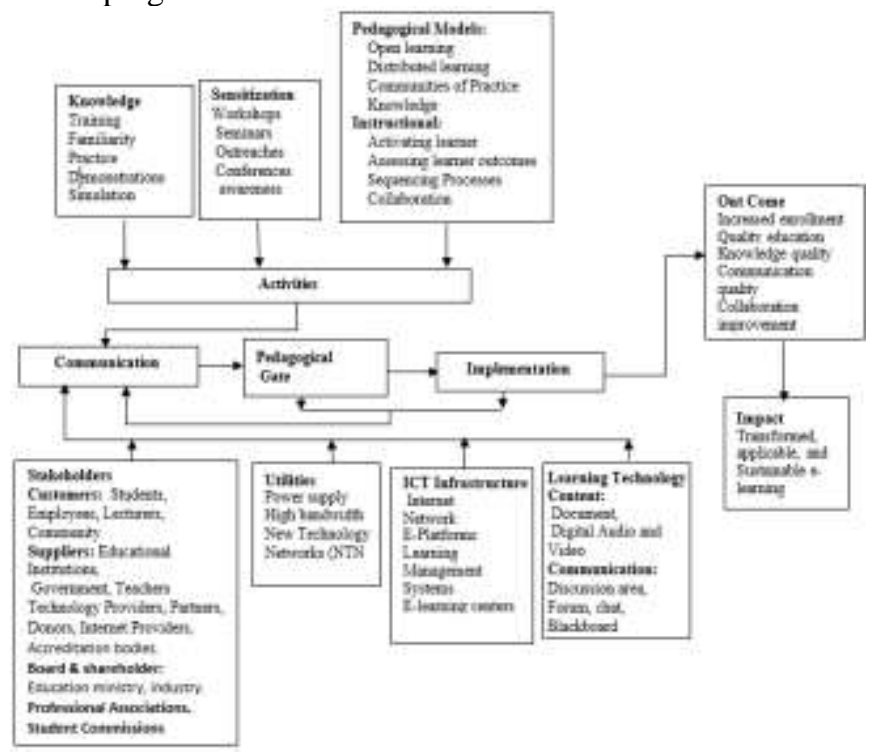

Figure 3: Basic e-learning framework

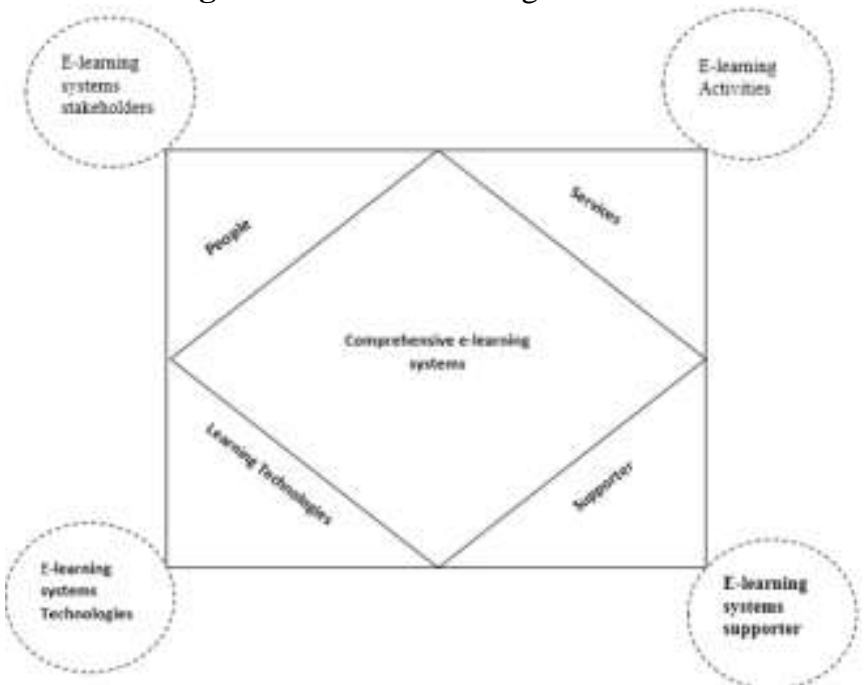

Figure 4: Comprehensive e-learning Systems Conceptual framework. Adapted from [8]

\section{Conclusions and Research Implications}

Following the discussions in this study, evidence of elearning implementation challenges has been identified and brought forward. However, for the case of developing countries, governments in developing countries seem not to have an e-learning implementation approach that includes applicable e-learning policies in public universities in particular. Yes, some policies do exist but have not been implemented to affect the eLearning phenomenon in developing countries.

The second gap is serious campaigns by the government including sensitizing all the stakeholders about the advantages of e-learning. Sensitization would help people understand the real values of e-learning vs. face-to-face(f2f) learning.

Thirdly, there would be an e-learning support system to cater for utilities and ICTs Infrastructure. This would include an elearning center in each public university to cater for ICTs Infrastructure and utilities.

Fourthly, the theoretical frameworks reviewed were not comprehensive. A comprehensive otherwise known as grounded theory is necessary to provide a better understanding about e-learning implementation challenges and the major constructs to address the situation.

Fifthly, some of the methods used in the previous studies included content analysis, which might have analyzed elearning challenges on-line while omitting other important issue.

Sixthly, combining case studies with other methods might lead to better results than using only case studies. The grounded analysis of the articles in this study has led to the identification of frequently e-learning challenges constructs that have been organized to design and develop a comprehensive e-learning framework that can serve as a baseline in the emerging field of e-learning implementation. Although this baseline is marked with limitations it takes the current state of e-learning implementation challenges that has yield several implications and reasonable insights to serve as a guide by researchers in the future research.

\section{Limitations}

The theories considered above as the basis for developing a conceptual framework for this study might not be containing all the constructs required for e-learning implementation challenges but served as a baseline for theorizing the framework that lead to solving some challenges associated with e-learning in the developing world.

Secondly, although the library for this literature was drawn from databases that generated more than 130 articles, it is not guaranteed that all the articles about e-learning challenges in developing countries were exhausted because this study is a research study with no specific research outlets. Secondly, the library used this study falls short as it does not consider Articles that did not have publication dates and did not have authors.

Thirdly, the library also considered articles that were published in developed countries about challenges of elearning in developed countries. This could have caused some bias in the findings as the researchers might have used telephone call to gather results without actually visiting the sites.

Fourthly, findings from literature can contain errors which the reviewer might not reveal. So, the findings used by the researcher in this study serve as a baseline up on which other researchers might use to conduct further research.

\section{Volume 6 Issue 12, December 2017}




\section{International Journal of Science and Research (IJSR) \\ ISSN (Online): 2319-7064}

Index Copernicus Value (2015): 78.96 | Impact Factor (2015): 6.391

\section{References}

[1] LLC. Epignosis, "E-Learning Concepts, Trends, Applications", 2014. Available: https://www.talentlms.com/elearning/elearning-101jan2014-v1.1.pdf. [Accessed: Oct.30,2017]

[2] Virtual college, "The Digital Divide-Barriers to elearning", The Australian Institute for Social Research (2006), University of Adelaide, Australia, 2016. Available:

http://www.umic.pt/images/stories/publicacoes/barriers _digitaldivide.pdf. [Accessed Nov.6, 2017]

[3] G. Ryan, "Guidance notes on planning a systematic review", $2010.2 \quad$ Available: https://www.tcd.ie/library/support/subjects/psychology/ Guidance\%20on\%20planning\%20a\%20systematic\%20 review\%20(2).pdf. [Accessed Oct.30,2017].

[4] O. Omer, T. Klomsri, M. Tedre, I. Popova, M.K. Allvin, F. Osman, "E-learning Opens Door to the Global Community: Novice Users' Experiences of Elearning in a Somali University", MERLOT Journal of Online Learning and Teaching 11(2), pp.267, 2015

[5] V. Venkatesh, "Determinants of perceived ease of use: Integrating control, intrinsic motivation, and emotion into the technology acceptance model", Journal of Information Systems Research, 11(4), pp. 342-365, 2000

[6] V. Venkatesh, M. G. Morris, G. B. Davis, F.D. Davis, "User acceptance of information technology: Toward a unified view", Journal of Management Information Systems(MIS) quarterly, pp.425-478, 2003

[7] K. G. Mayoka, R. Kyeyune, "An Analysis of Elearning Information System Adoption in Ugandan Universities: Case of Makerere University Business School. Information Technology Research Journal Vol.2(1), pp. $1-7$, April 2012

[8] M. Aparicio, F. Bacao, T. Oliveira, "An e-Learning Theoretical Framework", Journal of Educational Technology and Society, 19 (1), pp. 292-307, 2016

\section{Author Profile}

Lawrence Nkamwesiga received the Bachelor's degree in Information Technology and Computing(BITC) from Kyambogo University and Master of Science degree in Telecommunication Technology(MScTT) from Sikkim Manipal University in 2008 and 2013 , respectively. He is now a lecturer in information systems at Muni University, one of the public universities in Uganda. He also started his doctoral degree in formation technology at Walden University in 2014-2016 before he joined ICT University in Cameroon of which he is a $\mathrm{PhD}$ candidate pursuing a $\mathrm{PhD}$ degree in ICT. 